\title{
Grape Pomace Extracted Tannin for Green Synthesis of Silver Nanoparticles: Assessment of Their Antidiabetic, Antioxidant Potential and Antimicrobial Activity
}

\author{
Rijuta Ganesh Saratale ${ }^{1}$, Ganesh Dattatraya Saratale ${ }^{2}$ (D) Somin Ahn ${ }^{2}$ and Han-Seung Shin ${ }^{2, *}$ \\ 1 Research Institute of Biotechnology and Medical Converged Science, Dongguk University-Seoul, \\ Ilsandong-gu, Goyang-si 10326, Gyeonggi-do, Korea; rijutaganesh@gmail.com \\ 2 Department of Food Science and Biotechnology, Dongguk University-Seoul, Ilsandong-gu, \\ Goyang-si 10326, Gyeonggi-do, Korea; gdsaratale@dongguk.edu (G.D.S.); griju22@gmail.com (S.A.) \\ * Correspondence: spartan@dongguk.edu
}

check for updates

Citation: Saratale, R.G.; Saratale, G.D.; Ahn, S.; Shin, H.-S. Grape Pomace Extracted Tannin for Green Synthesis of Silver Nanoparticles: Assessment of Their Antidiabetic, Antioxidant Potential and Antimicrobial Activity. Polymers 2021, 13, 4355. https://doi.org/10.3390/ polym13244355

Academic Editor: Suguna Perumal

Received: 23 November 2021 Accepted: 10 December 2021 Published: 13 December 2021

Publisher's Note: MDPI stays neutral with regard to jurisdictional claims in published maps and institutional affiliations.

Copyright: (c) 2021 by the authors. Licensee MDPI, Basel, Switzerland. This article is an open access article distributed under the terms and conditions of the Creative Commons Attribution (CC BY) license (https:// creativecommons.org/licenses/by/ $4.0 /)$.

\begin{abstract}
In nanoscience, the "green" synthesis approach has received great interest as an eco-friendly and sustainable method for the fabrication of a wide array of nanoparticles. The present study accounts for an expeditious technique for the synthesis of silver nanoparticles (AgNPs) utilizing fruit waste grape pomace extracted tannin. Grape pomace tannin (Ta) involved in the reduction and capping of AgNPs and leads to the formation of stable Ta-AgNPs. Various conditions were attempted to optimize the particle size and morphology of Ta-AgNPs which was further analyzed using various analytical tools for different characteristic motives. UV-visible spectroscopy showed a characteristic peak at $420 \mathrm{~nm}$, indicating successful synthesis of AgNPs. Energy disperses spectroscopy (EDS) analysis proved the purity of the produced Ta-AgNPs and manifested a strong signal at $-2.98 \mathrm{keV}$, while Fourier-transform infrared spectrophotometer (FTIR) spectra of the Ta-AgNPs displayed the existence of functional groups of tannin. Zeta potential measurements $(-28.48 \mathrm{mV})$ showed that the Ta-AgNPs have reasonably good stability. High resolution transmission electron microscopy (HR-TEM) analysis confirmed the average dimension of the synthesized NPs was estimated about 15-20 nm. Ta-AgNPs potentials were confirmed by in vitro antidiabetic activity to constrain carbohydrate digesting enzymes, mainly $\alpha$-amylase and $\alpha$-glucosidase, with a definite concentration of sample displaying $50 \%$ inhibition ( $\mathrm{IC}_{50}$ ), which is about 43.94 and $48.5 \mu \mathrm{g} / \mathrm{mL}$, respectively. Synthesized Ta-AgNPs exhibited significant antioxidant potential with respect to its 2,2'-azino-bis(3-ethylbenzothi-azoline-6-sulfonic acid) (ABTS) (IC 50 of $40.98 \mu \mathrm{g} / \mathrm{mL}$ ) and 2,2-diphenyl-1-picrylhydrazyl (DPPH) (IC 50 of $53.98 \mu \mathrm{g} / \mathrm{mL})$ free radical scavenging activities. Ta-AgNPs exhibited extraordinary antibacterial activity against selected pathogenic strains and showed comparable antimicrobial index against ampicillin as a positive control.
\end{abstract}

Keywords: grape pomace; silver nanoparticles (AgNPs); in vitro antidiabetic activity; DPPH; antibacterial activity

\section{Introduction}

Owing to distinctive physical, chemical, optical, catalytic, and magnetic properties, nanomaterials have gained considerable attention for various biological, pharmaceutical, and electronic applications [1]. In recent times, research interest towards nanotechnology has improved which leads to the augmented growth in the production of nanomaterial and its market. Based on their size, nanomaterials are differently grouped, such as nanoparticles, dendrimers, nanotubes and nanofilms [2]. Further, this upsurges the diversity of nanoscale materials. A plethora of advancements in the methodologies for the synthesis of nanoparticles with different characteristics put them together as the most applicable and widely used in materials science. Two conventional production processes, mainly (a) electrochemical and chemical reduction and (b) photochemical and physical vapor 
condensation, are used for industrial scale nanomaterial production to achieve perfect shapes and higher purity [3]. However, these processes are energy demanding and require hazardous reagents (stabilizing and reducing agents), thus are not eco-friendly and cost-effective. Hence, there is an extensive demand for the definition of less demanding production technologies that would expand the affordability of the whole nanotechnology industry $[4,5]$.

Green synthesis is accomplished by combining metal salts with natural reducing agents (such as plant extracts, fruit extracts, and their secondary metabolites), microbial extracts and their by-products (such as vitamins, sugars, and biodegradable polymers) to create nanomaterials $[2,6]$. The green synthesis of NPs by employing green chemistry principles (Figure 1) is gaining abundant attraction for the development of these future nanosized materials. Plant extract-based nanoparticle synthesis is a non-toxic, eco-friendly, sustainable, and economical way and can perform under aqueous conditions, with low energy requirements and does not require toxic chemicals. Moreover, nanoparticle synthesis by plant extracts is comparatively much faster than the microbial route and easily scalable to produce NPs in huge quantities $[7,8]$. The fruit and fruit peel extracts contain various pharmacological compounds which function as reducing and capping compounds in the fabrication of different kinds of nanoparticles [9-11].

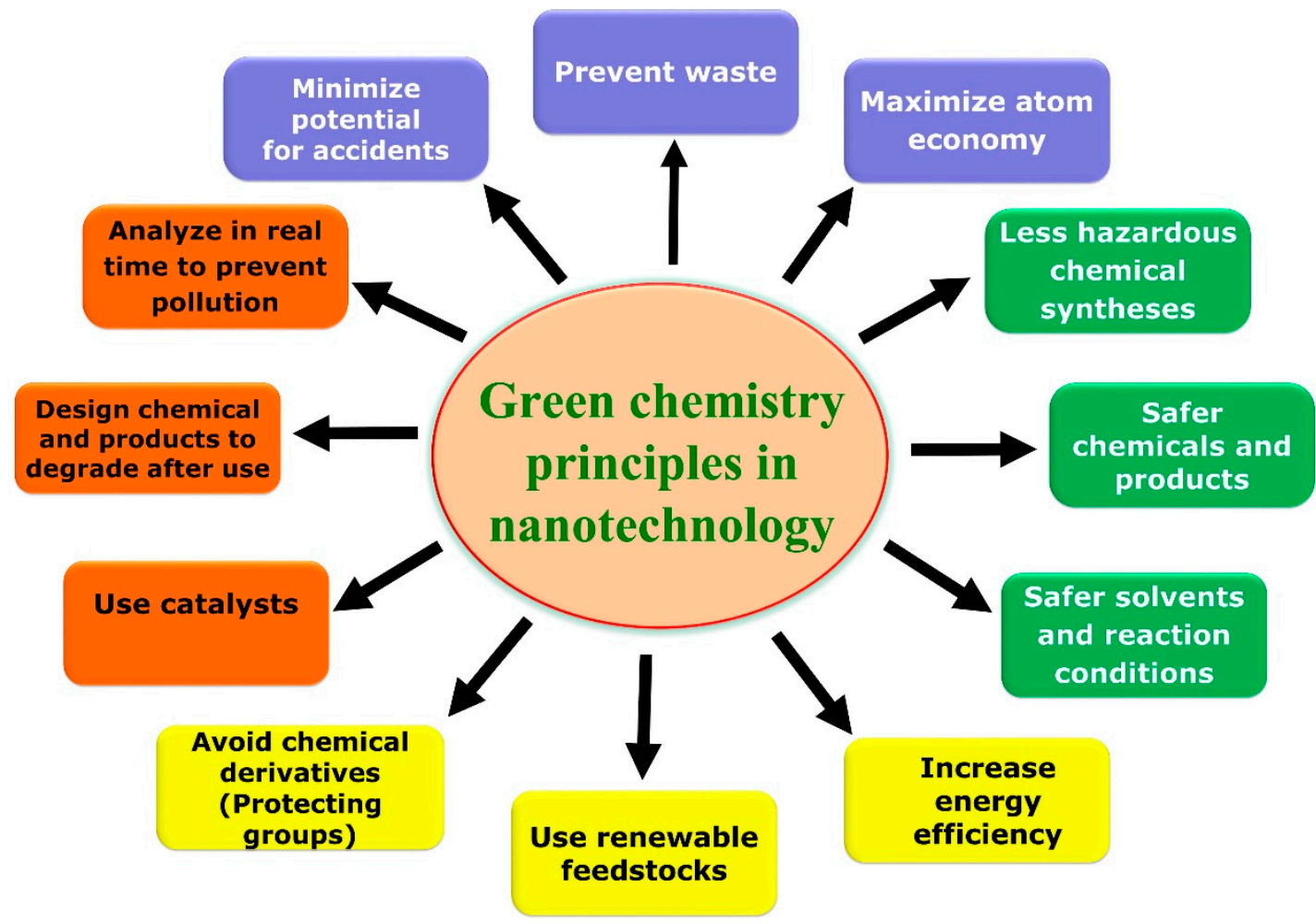

Figure 1. Overview of green chemistry principles applied in green nanotechnology.

Silver nanoparticles (AgNPs) have drawn more attention from various entrepreneurs due to their wide range of scope in numerous industries, such as agriculture, pharmacy, pigments, catalysis, electronics, and cosmetics. Other incredible properties of AgNPs include higher conductivity nature, chemical stability, which increases its potential in pharmaceutical applications mainly, cancer treatment, medical imaging, and drug delivery with reduced undesired toxicity $[6,12]$.

Grape (Vitas vinifera) can be considered as one of the largest fruit crops; about $>67$ million tons of grapes are produced per annum globally. Grapes are mainly used for wine production. All through the manufacture of grapes-wine, a major extent of solid organic by-product as a grape pomace is produced (about $40 \%$ ). Grape pomace signifies a vital 
source of phenolic antioxidants and can be utilized as an animal feed supplement with health promoting factors $[13,14]$. However, utilization of the huge amount of grape pomace is still scarce, thus it accumulates near wine industries as a waste product and causes environmental and disposal complications. High levels of condensed tannins are held back as residue, based on the low extraction during winemaking. Tannin is a polyphenolic compound, having human health benefits due to higher antioxidant potential $[11,15]$. The present study was intended for silver nanoparticles green synthesis using Vitis vinifera (extracted grape pomace tannin), which has not been studied well in nano research. Further, the influence of several operational factors in the synthesis of Ta-AgNPs were critically examined and optimized. Characterization of Ta-AgNPs with regard to the size and size distribution morphology and structure of particle size was accomplished using various standard analytical techniques. Ta-AgNPs were assessed for multi biogenic potentials in terms of in vitro antidiabetic and antioxidant activities by employing standard enzyme assays. Finally, the antimicrobial efficacy was investigated against pathogenic bacteria cultures to raise their potential applications in biomedical sectors.

\section{Materials and Methods}

\subsection{Grape Tannin Extraction and Reagents}

Grape pomace (GP) was procured from the local wine industry, washed and oven dried, until a persistent weight was attained. Further, the dried GP was cut into small pieces and finely ground. Tannin extraction from grape pomace was performed using the methodology reported elsewhere [16]. The finely ground grape pomace was added in water comprising of $\mathrm{Na}_{2} \mathrm{CO}_{3}(2.5 \%)$ and $\mathrm{Na}_{2} \mathrm{SO}_{3}(2.5 \%)$ aqueous base solution at $80{ }^{\circ} \mathrm{C}$ for $4 \mathrm{~h}$ followed by the filtration, and the resultant portion was spray-dehydrated and the resulting powder was utilized for the synthesis of silver nanoparticles and for subsequent procedures. Silver nitrate $\left(\mathrm{AgNO}_{3}\right)$, ascorbic acid, 2,2-diphenyl-1-picryhydrazyl (DPPH), 2,2'-Azino-bis(3-ethylbenzothiazoline)-6 sulfonic acid (ABTS), sodium potassium tartrate, 3,5 -dinitrosalicylic acid (DNS), acarbose, $\alpha$-glucosidase, and $\alpha$-amylase, were procured from Sigma-Aldrich, St. Louis, MO, USA. All other reagents and chemicals used for the study were of analytical grade quality and of higher pureness. Double distilled water was used throughout in all the experiments for solution preparations (Millipore Corporate, Billerica, MA, USA).

\subsection{Green Mode Synthesis of Ta-AgNPs, Optimization of Conditions and Stability Studies}

The synthesis of Ta-AgNPs was performed in the aqueous grape pomace extracted tannin, which is a reducing agent and silver nitrate $\left(\mathrm{AgNO}_{3}\right)$, as the precursor compound. Grape tannin $(1000 \mathrm{ppm})$ and the $\mathrm{AgNO}_{3}$ solution $(1 \mathrm{mM})$ were individually prepared. Appropriate volumes of tannin and $\mathrm{AgNO}_{3}$ solution (ratio of 1:10) in a flask were gradually mixed at $30{ }^{\circ} \mathrm{C}$ on a magnetic stirrer. At regular time intervals, the samples were collected from the reaction mixture and studied for their absorption spectrum by employing UVvisible absorption spectroscopy. The change in color (light brown and became darker) was also noted. In order to improve the properties and analytical merit of Ta-AgNPs, the reaction conditions, such as $\mathrm{pH}$ value $(2,3,4,5,6,7$, and 8$)$, reaction time $(0,5,10,20$ and $30 \mathrm{~min})$, concentration of $\mathrm{AgNO}_{3}(0.5,1.0,2.0$, and $2.5 \mathrm{mM})$, and tannin concentration by means of varied mixing ratios of Ta: $\mathrm{AgNO}_{3}(1: 1,1: 5,1: 8,1: 10,1: 15$, and 1:20), were inspected in a detailed manner. The optimization of NP synthesis factors was diversified one at a time by upholding the other variable stable factors. Under optimized conditions the produced Ta-AgNPs were concentrated and separated from the reaction mixture by setting a centrifuge at 12,000 rpm for $20 \mathrm{~min}$ (Labogene, 1736R, Lillerød, Denmark). The resulting Ta-AgNPs pellet was washed with distilled water to exclude the impurities and further dehydrated in an oven $\left(60^{\circ} \mathrm{C}\right)$ for analytical studies and biogenic potentials. The synthesized Ta-AgNPs were observed for up to 3 months for their stability, by keeping them at room temperature conditions and by applying the procedure reported earlier [9]. All experiments were conducted in triplicate sets. 


\subsection{Characterization of $\mathrm{Ta}-A g N P \mathrm{~s}$}

The optical property of Ta-AgNPs was determined between $300 \mathrm{~nm}$ and $700 \mathrm{~nm}$ at regular time intervals by using a UV-visible spectrophotometer (Optizen, Model-2120, Daejeon, Korea). The participation of several functional groups of extracted tannin during the bio-reduction and synthesis of Ta-AgNPs was analyzed using a Fourier-transform infrared spectrophotometer (Perkin-Elmer, Norwalk, CT, USA). Meanwhile, the spectrum of energy disperses spectroscopy (EDS; JEOL-64000, Tokyo, Japan) and element distribution of Ta-AgNPs was also measured. Zeta potential of Ta-AgNPs was assessed by a zeta potential analyzer (ELS-8000, Tokyo, Japan). A high resolution transmission electron microscopy (HR-TEM, Tecnai G2 20 S-TWIN, FEI Company, Loughborough, UK) was used to analyze the size, shape, and exterior morphology characteristics of Ta-AgNPs. The particle size of Ta-AgNPs was measured using the standard procedure [9].

\subsection{In Vitro Antidiabetic Potential of Synthesized Ta-AgNPs}

Antidiabetic potential of synthesized Ta-AgNPs was evaluated by measuring the inhibition capability against two types of carbohydrate hydrolyzing enzymes ( $\alpha$-amylase and $\alpha$-glucosidase). For the $\alpha$-amylase enzyme assay, a diverse quantity of synthesized Ta-AgNPs $(20,40,60,80$, and $100 \mu \mathrm{g} / \mathrm{mL}$; about $1 \mathrm{~mL})$ was added to $1 \mathrm{~mL}$ starch solution and kept at room temperature $\left(30^{\circ} \mathrm{C}\right)$ for $10 \mathrm{~min}$. Through adding $1 \mathrm{~mL}$ of dinitrosalicylic acid color reagent, the reaction was stopped and then kept in a boiling water bath for $10 \mathrm{~min}$ and further cooled. Finally, the absorbance was checked for the mixture at $540 \mathrm{~nm}$ in a colorimeter. The $\alpha$-glucosidase assay was performed according to the standard procedure and determined the inhibition of the enzyme activity by the Ta-AgNPs [17]. For the determination of both the enzyme assays, acarbose was considered as standard. Three replicated determinations were performed, and the averaged results were recognized to determine the antidiabetic potential of Ta-AgNPs. The enzyme activity was specified as of $\mathrm{IC}_{50}$ value (articulated as the definite concentration of a sample displaying 50\% inhibition).

$$
\text { Free radical scavenging }(\%)=[(\mathrm{AC}-\mathrm{AT}) / \mathrm{AC}] \times 100
$$

$\mathrm{AC}=$ absorbance of control; $\mathrm{AT}=$ absorbance after exposure to Ta-AgNPs.

\subsection{In Vitro Antioxidant Potential of Synthesized Ta-AgNPs}

Antioxidant potentials of ascorbic acid (as standard), extracted tannin, and synthesized Ta-AgNPs were investigated by quantifying the free radical scavenging activity against 2,2-diphenyl-1-picrylhydrazyl (DPPH) and 2,2-Azino-bis(3-ethylbenzothiazoline)-6 sulfonic acid (ABTS). The scavenging activity enzyme assays were conducted by employing the formerly described standard protocol [18]. The antioxidant activity of all samples was measured by taking the average mean values and standard deviation values and their scavenging potential was specified as of $\mathrm{IC}_{50}$ value using the previously described procedures.

\subsection{Antimicrobial Activity}

In vitro estimation for antibacterial efficacy of bio fabricated Ta-AgNPs was performed using Gram-negative and Gram-positive bacteria cultures (Escherichia coli and Staphylococcus aureus) through the standard Kirby-Bauer disc diffusion procedure [19]. First, in the nutrient broth the cultures were revived at $37^{\circ} \mathrm{C}$ overnight to attain optimum O.D. (0.4) at $600 \mathrm{~nm}$. Freshly grown overnight cultures were inoculated $(100 \mu \mathrm{L})$ and swabbed using sterilized cotton swabs on agar plates. Further, using sterile filter paper discs, extracted tannin, Ta-AgNPs, and Ampicillin were kept on the inoculated agar medium. For the uniform perfusion of the samples initially, the petri plates were left to stand for $1 \mathrm{~h}$, then incubated overnight at $37^{\circ} \mathrm{C}$ for $24 \mathrm{~h}$ for bacterial culture growth. Zone of inhibition was calculated $(\mathrm{mm})$ using a uniform scale round the disc infused with extracted tannin, Ta-AgNPs, and Ampicillin. Extracted tannin aqueous form was reflected as the negative control and ampi- 
cillin was applied as a positive control. The antimicrobial index of Ta-AgNPs against each pathogenic bacteria was measured and interpreted using the mentioned formula [20].

Antimicrobial index $=($ inhibition zone by Ta-AgNPs $/$ inhibition zone by ampicillin $) \times 100$

\subsection{Statistical Analysis}

All the experiments were conducted in three sets and the data of all the results calculated values were deliberated as mean \pm standard error mean (SEM). The data obtained were inferred by using the one-way analysis of a variance (ANOVA) test convoyed by a Tukey-Kramer multiple comparisons test.

\section{Results and Discussion}

\subsection{Ta-AgNPs Synthesis}

Tannin as a naturally occurring predominant phytomolecule in grape pomace possesses higher antioxidant activity [13]. Tannins were extracted from grape pomace and utilized for the synthesis and fabrication of Ta-AgNPs. Synthesis of Ta-AgNPs was visually marked by checking the color alteration of the reaction solution, from slight brown to dark brownish red, and also subjected to surface plasmon resonance (SPR) analysis by using UVvisible spectroscopy at various time intervals. The spectral analysis manifested a distinct SPR peak at $420 \mathrm{~nm}$ after $30 \mathrm{~min}$ of incubation (Figure 2). The absorption spectral peaks in the range of 410-450 were used for the characterization of the Ag nanoparticles [21]. In line with the Mie theory, spherical nanoparticles show only a single surface plasmon resonance (SPR) band, which supports our results [12]. The phenolic compounds are mainly responsible for this chelating ability due to the nucleophilic nature of their aromatic rings. During the NP synthesis process, $\mathrm{Ag}^{+}$ions are captured and chelated by extracted tannins, which subsequently undergo a reduction, nucleation, and capping process, resulting in the development of stable Ta-AgNPs [22]. The detailed schematic representation of the grape pomace tannin mediated synthesis of Ta-AgNPs has been presented in Figure 3.

\subsection{Optimization of Ta-AgNPs Synthesis Process Parameters}

To regulate the size and morphology of nanoparticles, the process parameters can be either optimized or modified. The solution $\mathrm{pH}$, temperature, reaction time, and phytochemical quantity are vital factors affecting the size, shape, and efficiency of the NP synthesis process $[22,23]$. Temperature is another significant process parameter, with an increase in temperature, the development of nucleation centers increases, which eventually upsurges the rate of nanoparticle synthesis. In this study, the SPR peak of produced Ta-AgNPs showed an increase in the absorption intensity from 30 to $40{ }^{\circ} \mathrm{C}$, while no difference at $40^{\circ} \mathrm{C}$ and $50^{\circ} \mathrm{C}$ was noted (Figure 4a). At a higher temperature $\left(60^{\circ} \mathrm{C}\right)$ a sharp reduction in SPR peak was discerned. Similarly, in other studies of AgNPs synthesis using plant extract, low reaction temperatures for stable nanoparticles synthesis relative to high temperatures were required [24].

For instance, alteration in the $\mathrm{pH}$ leads to change in the overall charge of bioactive phytomolecules, which in turn facilitates their binding affinity and hence bioreduction of metal ions into nanoparticles. During the synthesis of Ta-AgNPs at different $\mathrm{pH}$ of the reaction media, maximum SPR distinct peak was recorded at $\mathrm{pH} 7.0$ while other $\mathrm{pH}$ values found were not significant in the synthesis of Ta-AgNPs (Figure 4b). Nindawat and Agrawal [25] showed that Arnebia hispidissima extract promoted synthesis of small size AgNPs at alkaline $\mathrm{pH}$ levels of 7.0, 9.0 and 11.0, whereas flat UV spectrum was observed at $\mathrm{pH} 3.0$, which support our results. The effect of the initial concentrations of silver nitrate from $0.5 \mathrm{mM}$ to $2.5 \mathrm{mM}$ on Ta-AgNPs synthesis was studied. The results suggested a distinct upsurge peak up to $1.0 \mathrm{mM}$ (Figure $4 \mathrm{c}$ ). However, as the increase in silver nitrate concentration accelerates to decrease the SPR value, it might be due to the agglomeration of synthesized NPs. 

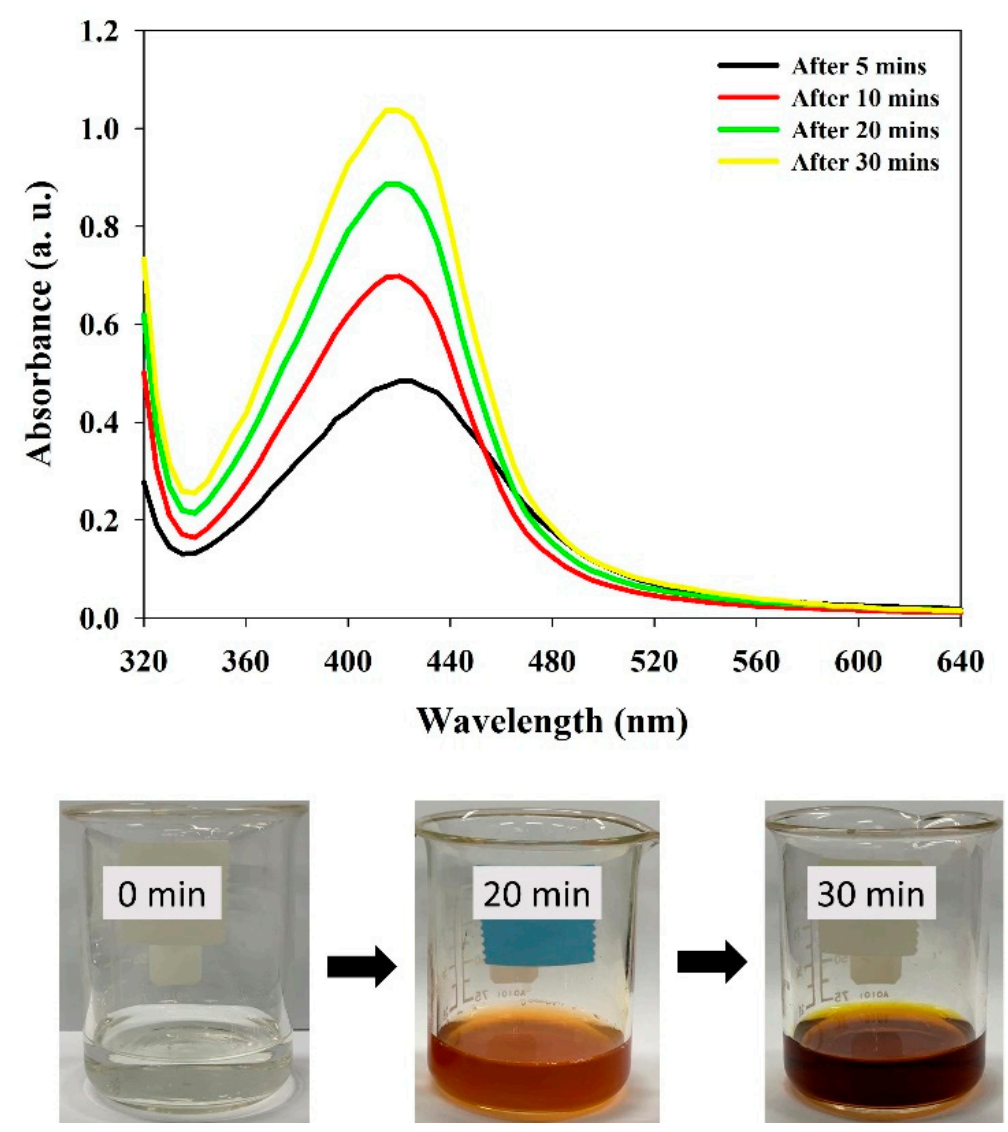

Figure 2. UV-visible absorption spectrum of synthesized Ta-AgNPs and the color changes in the reaction mixture at different time intervals.

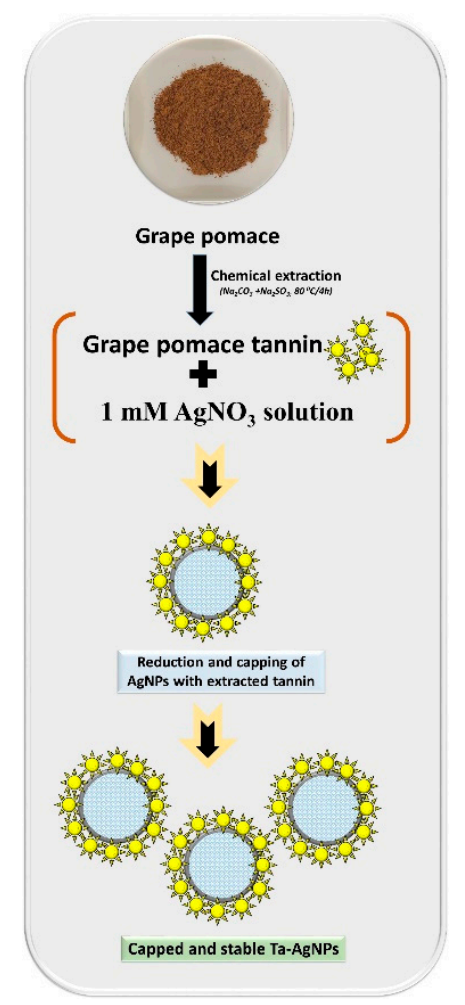

Figure 3. Schematic representation of the grape pomace tannin mediated synthesis of Ta-AgNPs. 

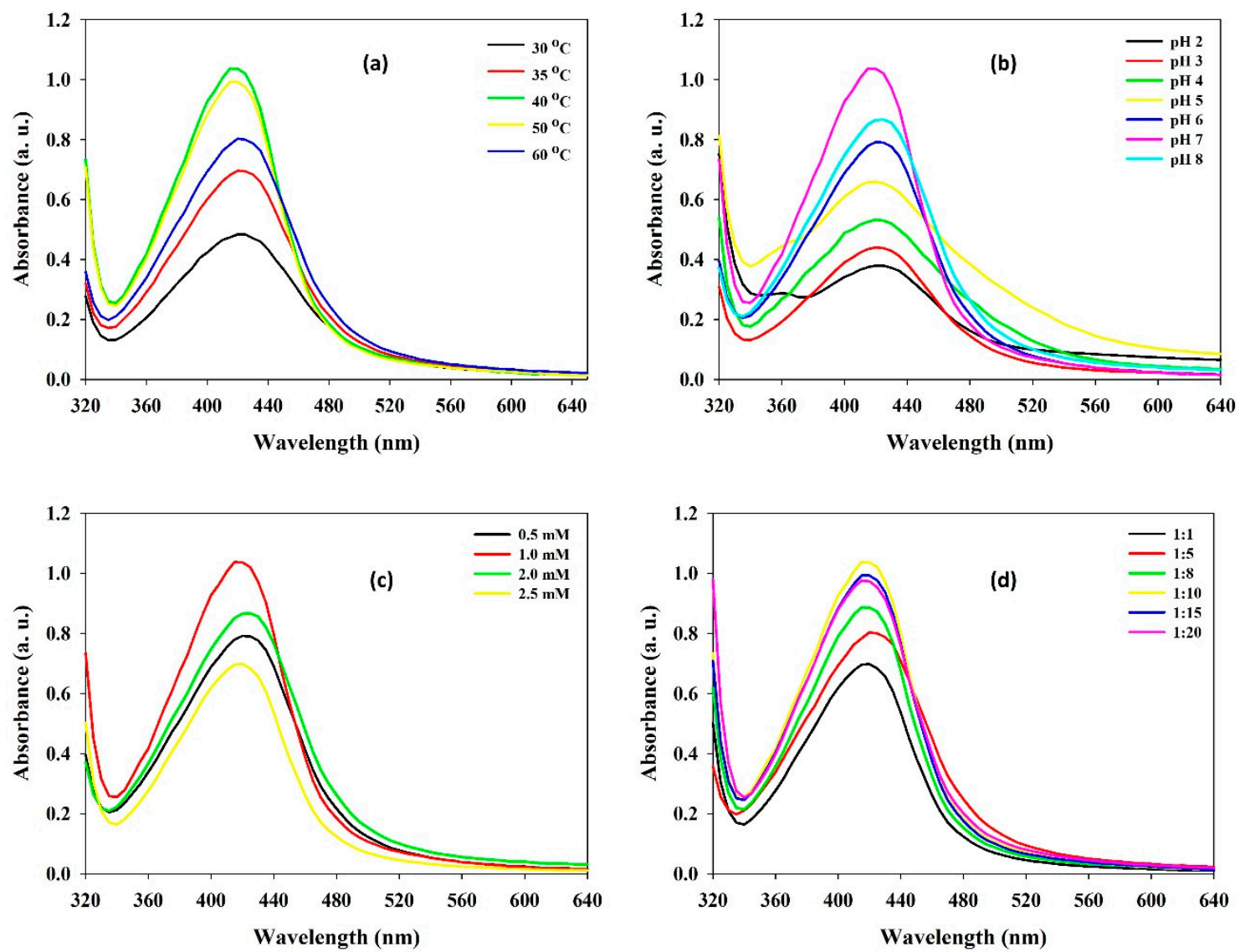

Figure 4. The effect of various influencing operational parameters (a) incubation temperature; (b) initial $\mathrm{pH}$; (c) $\mathrm{AgNO}_{3}$ concentration; and (d) Ta:AgNO 3 ratio on the synthesis of Ta-AgNPs and their UV-visible spectra.

High concentrations of polyphenols avoid coalescence and aggregation of nanoparticles; thus, determination of proper tannin concentration is essential. The effect of varying concentrations of tannins on Ta-AgNPs synthesis was investigated by making different mixing ratios of tannin and $\mathrm{AgNO}_{3}$. The results suggest that lower concentrations of tannin were found to be effective and the maximum SPR was noticed at a tannin and $\mathrm{AgNO}_{3}$ 1:10 ratio (Figure 4d). However, further decreasing the tannin concentration was found to be not effective in Ta-AgNPs synthesis [26]. The obtained results can be considered as noteworthy, which can help make the process worthwhile and commercially applicable. In accordance with the comprehensive results, the optimized parameters for Ta-AgNPs synthesis were $40{ }^{\circ} \mathrm{C}$ temperature, $\mathrm{pH}$ : 7.0, $1.0 \mathrm{mM} \mathrm{AgNO}$, Tannin $/ \mathrm{AgNO}_{3}$ ratio: 1:10, and $30 \mathrm{~min}$ incubation time, and were selected for further experimentation.

\subsubsection{Analytical Studies of Synthesized Ta-AgNPs}

Generally, nanoparticles are characterized on the basis of their morphology, size, surface area, zeta potential and dispersity index. A homogenous and monodispersed solution of these nanoparticles is extremely important for numerous applications.

$\mathrm{XRD}$ is generally advantageous to analyze the purity and monocrystalline nature of the nanoparticles $[9,27]$. X-rays penetrate deep into nanoparticles that generate a diffraction pattern, which is further compared with the standard for the collection of structural details. Measurements for the XRD of the Ta-AgNPs showed four distinct peaks at $2 \theta$ angles of $38.12,46.15,64.75$, and 76.54 attributes to (111), (200), (220), and (311) (Figure 5). The XRD spectrum of the synthesized AgNPs showed $2 \theta$ peak corresponding to 111 (at $38.1^{\circ}$ ) Bragg reflections of silver and also confirms the presence of face centered cubic (FCC) crystal structure. The results are in accordance with the silver nanoparticle synthesized by leaves of Panax ginseng confirmed the crystalline nature with FCC structure [28]. 




Figure 5. XRD pattern of Ta-AgNPs synthesized under optimized conditions.

\subsubsection{FTIR Analysis}

FTIR spectroscopy is used for the portrayal of the surface chemistry of nanoparticles and to identify the active functional groups [18]. FTIR analysis was carried out to discover the functional group deviations amongst grape pomace extracted tannins before and after it is fabricated on the surface of the AgNPs. FTIR spectra of extracted tannin and Ta-AgNPs are represented in Figure 6. The presence of broad absorption bands around $3254 \mathrm{~cm}^{-1}$ in both extracted tannin and synthesized Ta-AgNPs corresponds to the hydroxyl group (O-H) of polyphenol constituent [29]. Two peaks at 1582 and $1402 \mathrm{~cm}^{-1}$ are representative of the aromatic ring structures, whereas a small peak at $2922 \mathrm{~cm}^{-1}$ relates to the stretching of $\mathrm{C}-\mathrm{H}$ [11]. Moreover, the peaks in the region 1000 to $1300 \mathrm{~cm}^{-1}$ exhibited for aromatic ring vibration [16]. In a study, analogous outcomes have been observed in the silver nanoparticle synthesis using different forms of tannins (condensed and hydrolysable) extracted from chestnut, mangrove and quebracho [30]. FTIR results suggest the presence of polyphenolic and aromatic constituents of extracted tannins on the surface of Ta-AgNPs, which are involved in the reduction, capping and stabilizing the synthesized Ta-AgNPs.

\subsubsection{EDS and Zeta Potential Analysis}

Energy dispersive spectroscopy (EDS) is commonly used to calculate elemental composition and the purity investigation of synthesized AgNPs. The EDS measurement of the synthesized Ta-AgNPs showed the strongest absorption peak at $2.98 \mathrm{keV}$ corresponds to metallic silver due to surface plasmon resonance by silver atoms (Figure 7). The other minor peaks of $C$ and $S$ are related to tannin molecules, suggesting its involvement in the synthesis and fabrication of Ta-AgNPs. Few other studies confirmed that the adsorption of silver has been observed around $3 \mathrm{keV}$, which corresponds to the binding energy of elemental silver [11,28,31].

Further, the synthesized Ta-AgNps were studied by using zeta potential for the determination of surface charge. The analysis results showed the presence of higher negative surface charge $(-28.48 \mathrm{mV})$, which can prevent the NPs from agglomerating. Some researchers suggest that nanoparticle zeta potential values $>30$ or $<-30$ are comprised of high levels of stability [32]. This property is useful for the stability of synthesized NPs due to which SPR spectrum of Ta-AgNPs remain stable for about 3 months, and thus can be 
used in a continued way. Analogous zeta potential value $-28.4 \mathrm{mV}$ was perceived in the silver nanoparticles synthesized using Vitis vinifera skin extract [11,30].

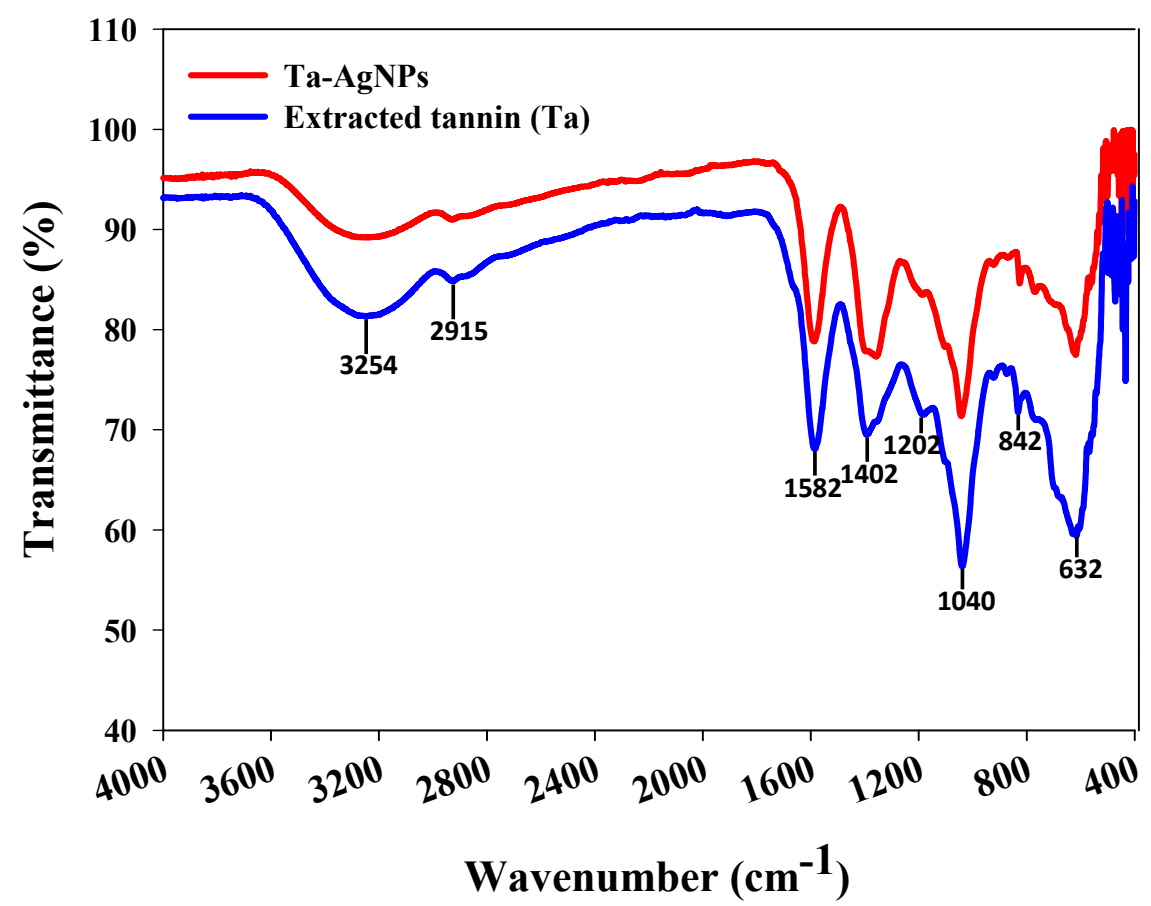

Figure 6. FTIR spectra of extracted tannin and Ta-AgNPs synthesized under optimized conditions.

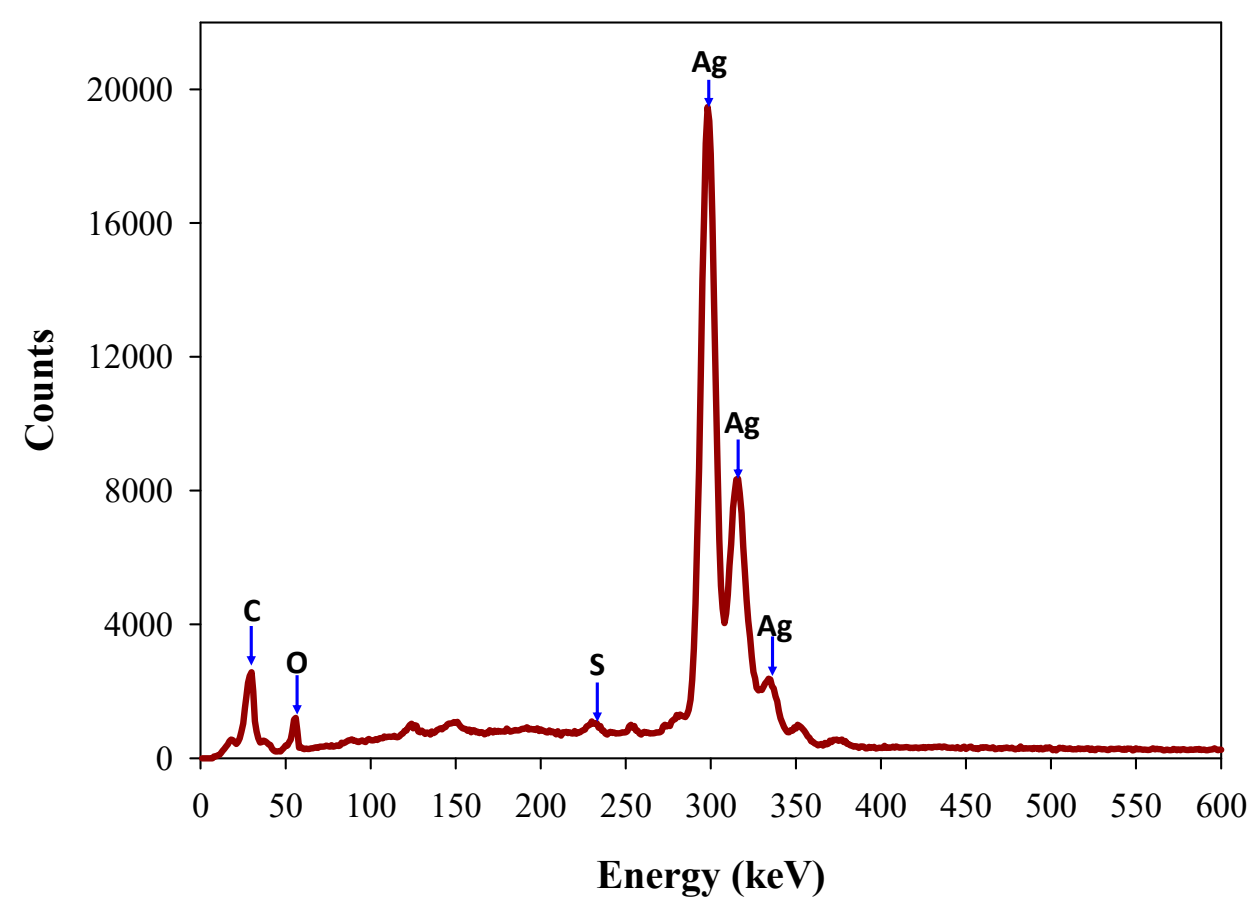

Figure 7. Energy dispersive spectroscopy (EDS) analysis of Ta-AgNPs synthesized under optimized conditions.

\subsubsection{HR-TEM Analysis}

Electron microscopy is another universally used technique for the analysis of the size and morphological characterization of nanoparticles. The TEM micrographs at different $50 \mathrm{~nm}$ and $20 \mathrm{~nm}$ magnifications revealed that the synthesized Ta-AgNPs are spherical in 
shape and uniformly distributed in the sample (Figure 8a,b), which aligns well with XRD and UV-visible spectroscopy results. TEM images also showed the presence of dark caps on the outer layer of nanoparticles which was due to the occurrence of tannin biomolecules on the surface of synthesized Ta-AgNPs. The particle histogram suggested the maximum NP size is in the range of 15 to $20 \mathrm{~nm}$ (Figure 8c), which increases its potential applicability in various sectors. Similar types of observations were recorded in the silver nanoparticles synthesized using Acacia nilotica leaf extract, jasmine flower extract, and aqueous extract of Dracocephalum kotschyi Boiss, respectively [31,33-35].
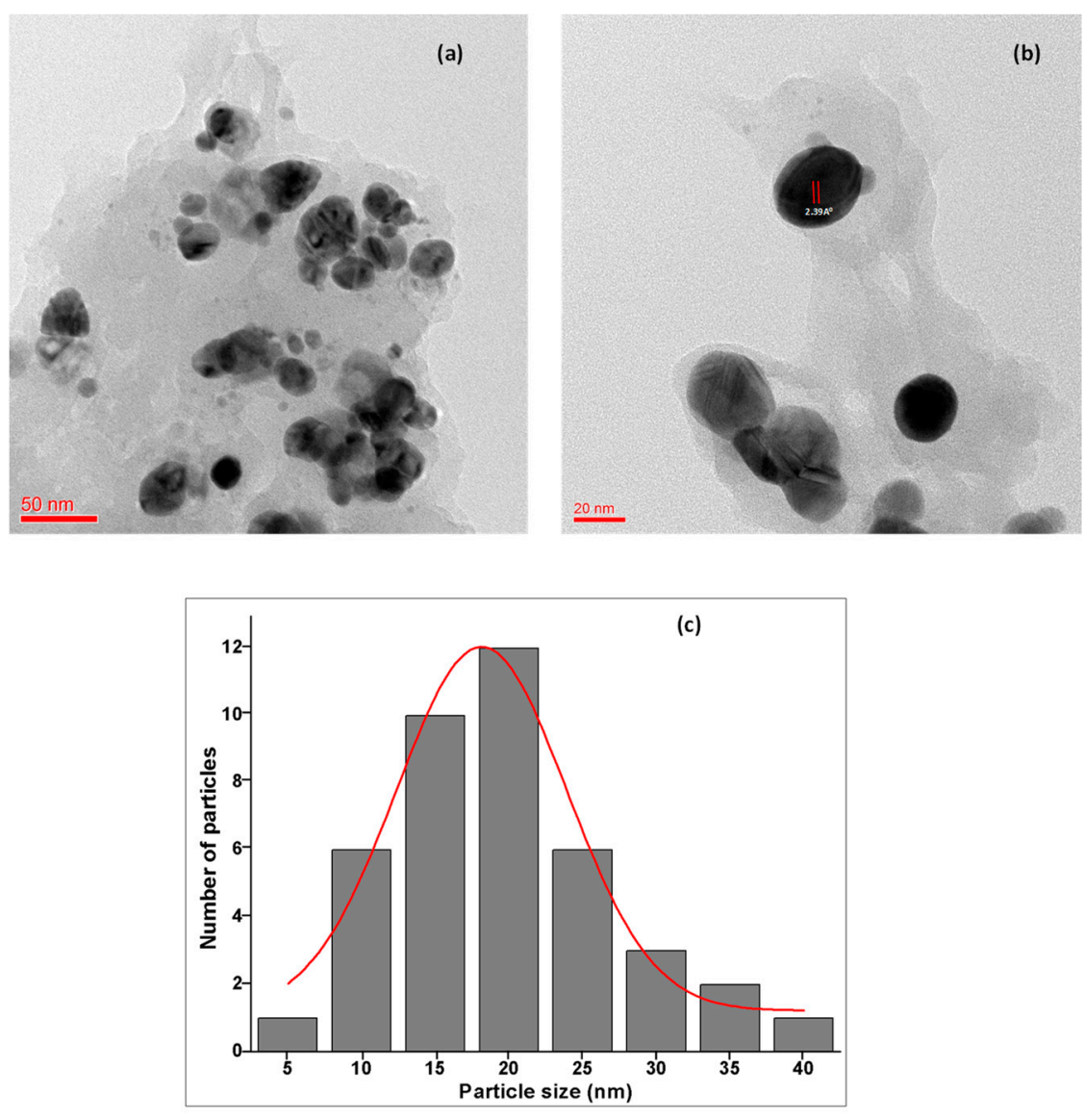

Figure 8. HR-TEM images of Ta-AgNPs: (a) at $50 \mathrm{~nm}$; (b) at $20 \mathrm{~nm}$ amplification; and (c) average particle size histogram of the Ta-AgNPs produced under optimized conditions.

\subsection{Biogenic Potential of Synthesized Ta-AgNPs}

The biogenic potential of the green synthesized Ta-AgNPs was assessed by investigating their antidiabetic, antioxidant, and antibacterial activities.

\subsubsection{Antidiabetic Potential}

The green synthesized silver nanoparticles have been established as highly stable and useful candidates for drug carriage because of their ultra-small size and unique physicochemical properties [7]. The capability to fine-tune the surface charge of the nanoparticle helps in targeting specific locations and the controlled release of drugs. $\alpha$-amylase and $\alpha$-glucosidase are accountable for hydrolyzing oligosaccharides or polysaccharides into $\alpha$-D-glucose which are adsorbed by intestinal cells, leading to postprandial hyperglycemia [36]. This unusual higher sugar level is responsible for the occurrence of type 2 diabetes (T2DM) which is troublesome and not easy to control. Acarbose, voglibose, and miglitol found clinically effective drugs to restrain or to treat T2DM by inhibiting the carbohydrate degrading enzymes [37]. However, these drugs are costly and also show adverse effects. To overcome this, there is a crucial requirement to establish effective NPs 
coated with natural products to control T2DM and sequential disorders. The synthesized Ta-AgNPs showed effective inhibition for both $\alpha$-amylase and $\alpha$-glucosidase enzyme activities in a dose dependent mode. The half-inhibitory concentration $\left(\mathrm{IC}_{50}\right)$ of Ta-AgNPs, extracted tannin and standard drug acarbose were determined and shown in Figure 9. The $\mathrm{IC}_{50}$ value of Ta-AgNPs and acarbose for $\alpha$-amylase and for $\alpha$-glucosidase were 43.94 and $40.2 \mu \mathrm{g} / \mathrm{mL}$ and 48.5 and $40.0 \mu \mathrm{g} / \mathrm{mL}$, respectively (Figure 9). Holoptelea integrifolia leaves mediated AgNPs showed antidiabetic potential against $\alpha$-amylase with significant $86.66 \%$ inhibition in enzyme activity [38]. In this study, the authors have proposed that synthesized AgNPs inhibit ATP-sensitive $\mathrm{K}^{+}$channel mechanism in beta cells of the pancreas.

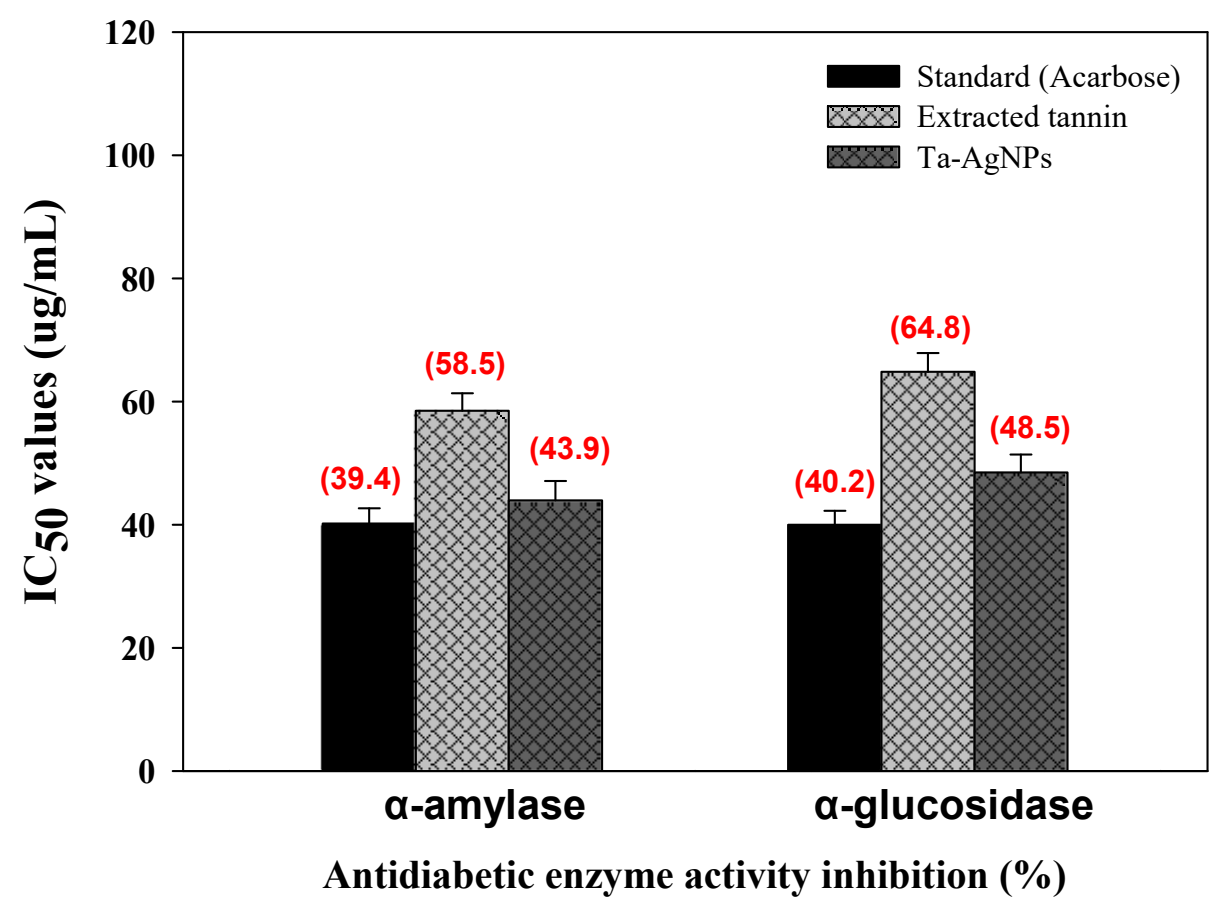

Figure 9. Antidiabetic potential of synthesized Ta-AgNPs, extracted tannin, and standard (acarbose) against $\alpha$-amylase and $\alpha$-glucosidase and their $\mathrm{IC}_{50}$ values.

\subsubsection{Antioxidant Potential}

Free radical generation is responsible for the existence of several pathological diseases, for instance cancer, heart disease, diabetes, Alzheimer's, hypertension, atherosclerosis, and aging [8]. The bio-synthesized Ta-AgNPs demonstrated significant antioxidant perspectives in terms of radical scavenging activities against stable free radical DPPH and ABTS and are presented in Figure 9. Ta-AgNPs displayed promising DPPH and ABTS free radicalscavenging activities in a concentration dependent mode. The standard catechol and synthesized Ta-AgNPs for DPPH and ABTS showed IC 50 values $(44.4$ and $43.8 \mu \mathrm{g} / \mathrm{mL}$ ) and (53.9 and $40.9 \mu \mathrm{g} / \mathrm{mL}$ ), respectively (Figure 10). In both enzymes only extracted tannin was found less effective and documented higher $\mathrm{IC}_{50}$ value $(70.8$ and $65.2 \mu \mathrm{g} / \mathrm{mL})$ relative to standard and Ta-AgNPs (Figure 10). In the case of grape seed and apple tannins, grape seed tannins displayed significantly more antioxidant activity than apple tannins [39]. The free-radical scavenging potential of biosynthesized nanoparticles and their application for the cure of different pathological conditions have been studied in vitro by several researchers $[9,25,40]$. The significant antidiabetic and antioxidant potential of Ta-AgNPs due to the tannin molecules are involved during the synthesis and fabrication of NPs. These molecules enhance the surface area of NPs, and their proper interaction leads to significant antidiabetic and antioxidant activities. 


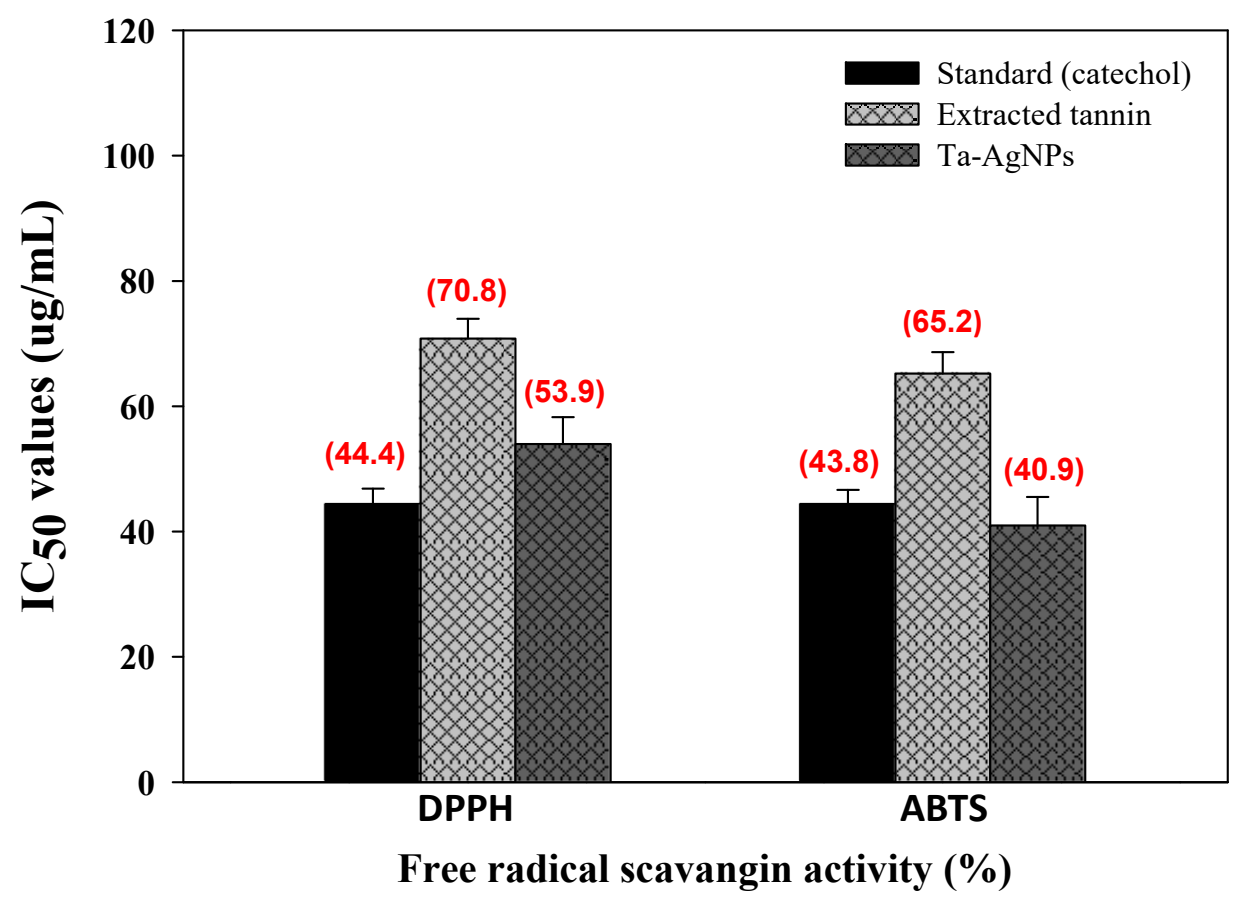

Figure 10. Antioxidant potential in terms of scavenging activity of synthesized Ta-AgNPs, extracted tannin, standard (catechol) against highly stable DPPH and ABTS and their $\mathrm{IC}_{50}$ values.

\subsubsection{Antibacterial Potential}

There has been emerging attention paid to exploring substitute approaches to developing novel antimicrobial agents since there is a continuous rise in multidrug resistant bacteria due to excess antibiotics use, mutation, and environmental circumstances [6,41]. The smaller sized nanoparticles have a superior binding surface area relative to larger NPs and show more potent antimicrobial activity. AgNPs found a potent antimicrobial agent. The synthesized Ta-AgNPs exhibited potential antibacterial activity towards the designated strains. The results are expressed as zone of the inhibition (ZOI) to define the comparative antibacterial potential of Ta-AgNPs and the results have been presented in Table 1. The obtained results revealed that the synthesized Ta-AgNPs executing significant antibacterial activity and can be used in the development of antibacterial drugs. It was supposed that Ta-AgNPs exhibited significant antibacterial effect, owing to its ability to penetrate the membrane and interact with cellular components, mainly destruction of respiratory enzymes, destruction of electron transport process, and DNA function, which leads to growth inhibition. Still, additional research is essential to understand the exact mechanisms of antibacterial activity by NPs. Disruption of membrane potential leads to cytoplasmic leakage, which results in the release of proteins and lipopolysaccharide molecules, and finally lysis of bacterial cells was observed [42]. AgNPs synthesized using the leaf extract of Neurada procumbens showed noteworthy antimicrobial activity against multidrug resistant Gram-negative pathogens Klebsiella pneumoniae, Acinetobacter baumannii and Escherichia coli [43]. Moreover, Hashim et al. [11], Escárcega-González et al. [41], and Kim et al. [44] also conveyed antibacterial activity of plant extract mediated AgNPs against S. epidermidis, S. aureus, Listeria monocytogenes; E. coli, P. aeruginosa, P. aeruginosa, B. subtilis; and E. coli, and S. aureus, respectively. 
Table 1. Assessment of antimicrobial activity of Ta-AgNPs against pathogenic microorganisms.

\begin{tabular}{ccccc}
\hline \multirow{2}{*}{ Pathogen } & $\begin{array}{c}\text { Ta-AgNPs } \\
\text { concentration } \\
(20 \mu \mathrm{g} / \mathrm{mL})\end{array}$ & $\begin{array}{c}\text { Positive control } \\
(20 \mu \mathrm{g} / \mathrm{mL})\end{array}$ & $\begin{array}{c}\text { Negative control } \\
(20 \mu \mathrm{g} / \mathrm{mL})\end{array}$ & $\begin{array}{c}\text { Antimicrobial } \\
\text { index }(\%)\end{array}$ \\
\hline Escherichia coli & $14.2 \pm 0.48$ & $15.2 \pm 0.52$ & $4.85 \pm 0.98$ & $93.4 \pm 2.05$ \\
\hline Staphylococcus aureus & $11.1 \pm 0.82$ & $13.7 \pm 0.65$ & $4.15 \pm 0.68$ & $81.0 \pm 2.35$ \\
\hline
\end{tabular}

Positive control—Ampicillin; negative control—extracted tannin. NA—no activity. Values are mean \pm standard
error of three replicates.

\section{Conclusions}

The fruit waste grape pomace extracted tannin was exploited for the synthesis of Ta-AgNPs for the potent approach as more cost effective and non-toxic, as well as useful in lessening the burden of grape pomace waste. Optimization of synthesis parameters and their characterization using various standard analytical techniques was performed. The results suggest the synthesized NPs are spherical, monodispersed and highly stable. Tannin fabricated AgNPs showed significant antidiabetic potential by inhibiting the marker carbohydrate hydrolyzing enzymes, namely $\alpha$-amylase and $\alpha$-glucosidase. Additionally, Ta-AgNPs showed promising antioxidant potential and antibacterial activity against pathogenic microorganisms. In consonance with all-inclusive results, Ta-AgNPs displayed a wide array of biological solicitations and can be recognized as attractive, eco-friendly material for its possible use in drug delivery, diabetes treatment, antibacterial activity, and cancer therapy, without negative effects.

Author Contributions: Conceptualization, R.G.S. and G.D.S.; methodology, R.G.S.; validation, R.G.S., H.-S.S. and G.D.S.; formal analysis, R.G.S., H.-S.S. and G.D.S.; investigation, R.G.S.; resources, H.-S.S.; data curation, R.G.S., H.-S.S. and G.D.S.; writing—original draft preparation, R.G.S. and G.D.S.; writing-review and editing, R.G.S., H.-S.S., S.A. and G.D.S.; supervision, H.-S.S. and G.D.S.; project administration, H.-S.S.; funding acquisition, H.-S.S. All authors have read and agreed to the published version of the manuscript.

Funding: This work was supported by the Korea Institute of Planning and Evaluation for Technology in Food, Agriculture and Forestry (IPET) through the High Value-added Food Technology Development Program funded by the Ministry of Agriculture, Food and Rural Affairs (MAFRA) (121017-03).

Acknowledgments: This work was supported by the Korea Institute of Planning and Evaluation for Technology in Food, Agriculture and Forestry (IPET) through the High Value-added Food Technology Development Program funded by the Ministry of Agriculture, Food and Rural Affairs (MAFRA) (121017-03).

Conflicts of Interest: There is no conflict of interest to declare.

\section{References}

1. Bouafia, A.; Laouini, S.E.; Ahmed, A.S.A.; Soldatov, A.V.; Algarni, H.; Chong, K.F.; Ali, G.A.M. The Recent Progress on Silver Nanoparticles: Synthesis and Electronic Applications. Nanomaterials 2021, 11, 2318. [CrossRef]

2. Saratale, R.G.; Karuppusamy, I.; Saratale, G.D.; Pugazhendhi, A.; Kumar, G.; Park, Y.; Ghodake, G.S.; Bharagava, R.N.; Banu, R.; Shin, H.S. A comprehensive review on green nanomaterials using biological systems: Recent perception and their future applications. Colloids Surf. B Biointerfaces 2018, 170, 20-35. [CrossRef] [PubMed]

3. Iravani, S.; Korbekandi, H.; Mirmohammadi, S.V.; Zolfaghari, B. Synthesis of silver nanoparticles: Chemical, physical and biological methods. Res. Pharm. Sci. 2014, 9, 385-406. [PubMed]

4. Kumar, L.H.; Kazi, S.N.; Masjuki, H.H.; Zubir, M.N.M. A review of recent advances in green nanofluids and their application in thermal systems. Chem. Eng. J. 2021, 429, 132321. [CrossRef]

5. Muo, I.; Azeez, A. Green Entrepreneurship: Literature Review and Agenda for Future Research. Int. J. Entrep. Knowl. 2019, 7, 17-29. [CrossRef]

6. Ahmad, S.A.; Das, S.S.; Khatoon, A.; Ansari, M.T.; Afzal, M.; Hasnain, S.; Nayak, A.K. Bactericidal activity of silver nanoparticles: A mechanistic review. Mater. Sci. Energy Technol. 2020, 3, 756-769. [CrossRef] 
7. Xue, H.; Tan, J.; Zhu, X.; Li, Q.; Cai, X. Counter-current fractionation-assisted and bioassay-guided separation of active compounds from cranberry and their interaction with $\alpha$-glucosidase. LWT Food Sci. Technol. 2021, 145, 111374. [CrossRef]

8. Dauthal, P.; Mukhopadhyay, M. Noble Metal Nanoparticles: Plant-Mediated Synthesis, Mechanistic Aspects of Synthesis, and Applications. Ind. Eng. Chem. Res. 2016, 55, 9557-9577. [CrossRef]

9. Saratale, R.G.; Shin, H.-S.; Kumar, G.; Benelli, G.; Ghodake, G.S.; Jiang, Y.Y.; Kim, D.S.; Saratale, G.D. Exploiting fruit byproducts for eco-friendly nanosynthesis: Citrus $\times$ clementina peel extract mediated fabrication of silver nanoparticles with high efficacy against microbial pathogens and rat glial tumor C6 cells. Environ. Sci. Pollut. Res. 2018, 25, 10250-10263. [CrossRef] [PubMed]

10. Hamelian, M.; Zangeneh, M.M.; Shahmohammadi, A.; Varmira, K.; Veisi, H. Pistacia atlantica leaf extract mediated synthesis of silver nanoparticles and their antioxidant, cytotoxicity, and antibacterial effects under in vitro condition. Appl. Organomet. Chem. 2019, 33, e5278. [CrossRef]

11. Hashim, N.; Paramasivam, M.; Tan, J.S.; Kernain, D.; Hussin, M.H.; Brosse, N.; Gambier, F.; Raja, P.B. Green mode synthesis of silver nanoparticles using Vitis vinifera's tannin and screening its antimicrobial activity/apoptotic potential versus cancer cells. Mater. Today Commun. 2020, 25, 101511. [CrossRef]

12. Vijayaraghavan, K.; Ashokkumar, T. Plant-mediated biosynthesis of metallic nanoparticles: A review of literature, factors affecting synthesis, characterization techniques and applications. J. Environ. Chem. Eng. 2017, 5, 4866-4883. [CrossRef]

13. Fontana, A.R.; Antoniolli, A.; Bottini, R. Grape Pomace as a Sustainable Source of Bioactive Compounds: Extraction, Characterization, and Biotechnological Applications of Phenolics. J. Agric. Food Chem. 2013, 61, 8987-9003. [CrossRef] [PubMed]

14. Friedman, M. Antibacterial, Antiviral, and Antifungal Properties of Wines and Winery Byproducts in Relation to Their Flavonoid Content. J. Agric. Food Chem. 2014, 62, 6025-6042. [CrossRef] [PubMed]

15. Mangan, J.L. Nutritional Effects of Tannins in Animal Feeds. Nutr. Res. Rev. 1988, 1, 209-231. [CrossRef] [PubMed]

16. Ping, L.; Pizzi, A.; Guo, Z.D.; Brosse, N. Condensed tannins from grape pomace: Characterization by FTIR and MALDI TOF and production of environment friendly wood adhesive. Ind. Crop. Prod. 2012, 40, 13-20. [CrossRef]

17. Balan, K.; Qing, W.; Wang, Y.; Liu, X.; Palvannan, T.; Wang, Y.; Ma, F.; Zhang, Y. Antidiabetic activity of silver nanoparticles from green synthesis using Lonicera japonica leaf extract. RSC Adv. 2016, 6, 40162-40168. [CrossRef]

18. Saratale, G.D.; Saratale, R.G.; Kim, D.-S.; Kim, D.-Y.; Shin, H.S. Exploiting Fruit Waste Grape Pomace for Silver Nanoparticles Synthesis, Assessing Their Antioxidant, Antidiabetic Potential and Antibacterial Activity Against Human Pathogens: A Novel Approach. Nanomaterials 2020, 10, 1457. [CrossRef]

19. Bauer, A.W.; Kirby, M.W.M.; Sherris, J.C.; Turck, M. Antibiotic Susceptibility Testing by a Standardized Single Disk Method. Am. J. Clin. Pathol. 1966, 45, 493-496. [CrossRef]

20. Duygu, D.Y.; Erkaya, I.A.; Erdem, B.; Yalçin, D. Characterization of silver nanoparticle produced by Pseudopediastrum boryanum (Turpin) E. Hegewald and its antimicrobial effects on some pathogens. Int. J. Environ. Sci. Technol. 2019, 16, 7093-7102. [CrossRef]

21. Chung, I.-M.; Park, I.; Seung-Hyun, K.; Thiruvengadam, M.; Rajakumar, G. Plant-Mediated Synthesis of Silver Nanoparticles: Their Characteristic Properties and Therapeutic Applications. Nanoscale Res. Lett. 2016, 11, 1-14. [CrossRef] [PubMed]

22. Velusamy, P.; Kumar, G.V.; Jeyanthi, V.; Das, J.; Pachaiappan, R. Bio-Inspired Green Nanoparticles: Synthesis, Mechanism, and Antibacterial Application. Toxicol. Res. 2016, 32, 95-102. [CrossRef]

23. Pinto, R.J.B.; Lucas, J.M.F.; Morais, M.P.; Santos, S.A.; Silvestre, A.J.; Marques, P.A.; Freire, C.S. Demystifying the morphology and size control on the biosynthesis of gold nanoparticles using Eucalyptus globulus bark extract. Ind. Crop. Prod. 2017, 105, 83-92 [CrossRef]

24. Azizi, S.; Mohamad, R.; Bahadoran, A.; Bayat, S.; Rahim, R.A.; Ariff, A.; Saad, W.Z. Effect of annealing temperature on antimicrobial and structural properties of bio-synthesized zinc oxide nanoparticles using flower extract of Anchusa italica. J. Photochem. Photobiol. B Biol. 2016, 161, 441-449. [CrossRef]

25. Nindawat, S.; Agrawal, V. Fabrication of silver nanoparticles using Arnebia hispidissima (Lehm.) A. DC. root extract and unravelling their potential biomedical applications. Artif. Cells Nanomed. Biotechnol. 2019, 47, 166-180. [CrossRef] [PubMed]

26. Gangwar, C.; Yaseen, B.; Kumar, I.; Singh, N.K.; Naik, R.M. Growth Kinetic Study of Tannic Acid Mediated Monodispersed Silver Nanoparticles Synthesized by Chemical Reduction Method and Its Characterization. ACS Omega 2021, 6, 22344-22356. [CrossRef]

27. Pirtarighat, S.; Ghannadnia, M.; Baghshahi, S. Green synthesis of silver nanoparticles using the plant extract of Salvia spinosa grown in vitro and their antibacterial activity assessment. J. Nanostruct. Chem. 2019, 9, 1-9. [CrossRef]

28. Singh, P.; Kim, Y.J.; Wang, C.; Mathiyalagan, R.; Yang, D.C. The development of a green approach for the biosynthesis of silver and gold nanoparticles by using Panax ginseng root extract, and their biological applications. Artif. Cells Nanomed. Biotechnol. 2015, 44, 1-8. [CrossRef]

29. Xu, H.; Wang, L.; Su, H.; Gu, L.; Han, T.; Meng, F.; Liu, C. Making Good Use of Food Wastes: Green Synthesis of Highly Stabilized Silver Nanoparticles from Grape Seed Extract and Their Antimicrobial Activity. Food Biophys. 2015, 10, 12-18. [CrossRef]

30. Raja, P.B.; Rahim, A.A.; Qureshi, A.K.; Awang, K. Green synthesis of silver nanoparticles using tannins. Mater. Sci.-Poland 2014, 32, 408-413. [CrossRef]

31. Saratale, R.G.; Saratale, G.D.; Cho, S.-K.; Ghodake, G.; Kadam, A.; Kumar, S.; Mulla, S.I.; Kim, D.-S.; Jeon, B.-H.; Chang, J.S.; et al. Phyto-fabrication of silver nanoparticles by Acacia nilotica leaves: Investigating their antineoplastic, free radical scavenging potential and application in $\mathrm{H} 2 \mathrm{O} 2$ sensing. J. Taiwan Inst. Chem. Eng. 2019, 99, 239-249. [CrossRef]

32. Lee, J.; Kim, T.; Choi, I.-G.; Choi, J. Phenolic Hydroxyl Groups in the Lignin Polymer Affect the Formation of Lignin Nanoparticles. Nanomaterials 2021, 11, 1790. [CrossRef] 
33. Orlowski, P.; Zmigrodzka, M.; Tomaszewska, E.; Soliwoda, K.; Czupryn, M.; Antos-Bielska, M.; Szemraj, J.; Celichowski, G.; Grobelny, J.; Krzyzowska, M. Tannic acid-modified silver nanoparticles for wound healing: The importance of size. Int. J. Nanomed. 2018, 13, 991-1007. [CrossRef] [PubMed]

34. Aravind, M.; Ahmad, A.; Ahmad, I.; Amalanathan, M.; Naseem, K.; Mary, S.M.M.; Parvathiraja, C.; Hussain, S.; Algarni, T.S.; Pervaiz, M.; et al. Critical green routing synthesis of silver NPs using jasmine flower extract for biological activities and photocatalytical degradation of methylene blue. J. Environ. Chem. Eng. 2021, 9, 104877. [CrossRef]

35. Chahardoli, A.; Qalekhani, F.; Shokoohinia, Y.; Fattahi, A. Biological and catalytic activities of green synthesized silvernanoparticles from the leaf infusion of Dracocephalum kotschyi Boiss. Glob. Chall. 2021, 5, 2000018. [CrossRef] [PubMed]

36. Zhang, J.; Sun, L.; Dong, Y.; Fang, Z.; Nisar, T.; Zhao, T.; Wang, Z.-C.; Guo, Y. Chemical compositions and $\alpha$-glucosidase inhibitory effects of anthocyanidins from blueberry, blackcurrant and blue honeysuckle fruits. Food Chem. 2019, 299, 125102. [CrossRef]

37. Imran, S.; Taha, M.; Ismail, N.H.; Kashif, S.M.; Rahim, F.; Jamil, W.; Hariono, M.; Yusuf, M.; Wahab, H. Synthesis of novel flavone hydrazones: In-vitro evaluation of $\alpha$-glucosidase inhibition, QSAR analysis and docking studies. Eur. J. Med. Chem. 2015, 105, 156-170. [CrossRef] [PubMed]

38. Kumar, V.; Singh, S.; Srivastava, B.; Bhadouria, R.; Singh, R. Green synthesis of silver nanoparticles using leaf extract of Holoptelea integrifolia and preliminary investigation of its antioxidant, anti-inflammatory, antidiabetic and antibacterial activities. J. Environ. Chem. Eng. 2019, 7, 103094. [CrossRef]

39. Figueroa Espinoza, M.C.; Zafimahova, A.; Alvarado, P.G.; Dubreucq, E.; Legrand, C.P. Grape seed and apple tannins: Emulsifying and antioxidant properties. Food Chem. 2015, 178, 38-44. [CrossRef]

40. Rajaram, K.; Aiswarya, D.C.; Sureshkumar, P. Green synthesis of silver nanoparticle using Tephrosia tinctoria and its anti-diabetic activity. Mater. Lett. 2015, 138, 251-254. [CrossRef]

41. Escárcega-González, C.E.; Garza-Cervantes, J.A.; Vazquez-Rodríguez, A.; Montelongo-Peralta, L.Z.; Treviño-González, M.; Castro, E.D.B.; Saucedo-Salazar, E.; Morales, R.C.; Soto, D.R.; González, F.T. In vivo antimicrobial activity of silver nanoparticles produced via a green chemistry synthesis using Acacia rigidula as a reducing and capping agent. Int. J. Nanomed. 2018, 13, $2349-2363$. [CrossRef] [PubMed]

42. Gahlawat, G.; Shikha, S.; Chaddha, B.S.; Chaudhuri, S.R.; Mayilraj, S.; Choudhury, A.R. Microbial glycolipoprotein-capped silver nanoparticles as emerging antibacterial agents against cholera. Microb. Cell Fact. 2016, 15, 1-14. [CrossRef] [PubMed]

43. Alharbi, F.A.; Alarfaj, A.A. Green synthesis of silver nanoparticles from Neurada procumbens and its antibacterial activity against multi-drug resistant microbial pathogens. J. King Saud Univ. Sci. 2020, 32, 1346-1352. [CrossRef]

44. Kim, M.; Jee, S.-C.; Shinde, S.K.; Mistry, B.M.; Saratale, R.G.; Saratale, G.D.; Ghodake, G.S.; Kim, D.-Y.; Sung, J.-S.; Kadam, A.A. Green-Synthesis of Anisotropic Peptone-Silver Nanoparticles and Its Potential Application as Anti-Bacterial Agent. Polymers 2019, 11, 271. [CrossRef] [PubMed] 